\title{
Preventing the emergence of Ebola disease in unaffected countries: necessity of preparedness
}

\author{
${ }^{*}$ Correspondence to: Saurabh RamBihariLal Shrivastava, \\ Email: drshrishri2008@gmail.com \\ Copyright: ๑ 2014 by Kerman University of Medical Sciences \\ Citation: Shrivastava SR, Shrivastava PS, Ramasamy J. Preventing the emergence \\ of Ebola disease in unaffected countries: necessity of preparedness. Int J Health Policy \\ Manag 2014; 3: 417-418. doi: 10.15171/ijhpm.2014.117 \\ Received: 21 October 2014, Accepted: 1 November 2014, ePublished: 1 November 2014
}

Saurabh RamBihariLal Shrivastava ${ }^{*}$, Prateek Saurabh Shrivastava, Jegadeesh Ramasamy

\section{Dear Editor,}

The outbreak of Ebola disease in West-African nations have come as a wake-up call for the international health agencies and the public health authorities of the affected nations as well (1). This outbreak has shown to the world that even a disease which is almost forty years old, and which was detected on at-least twenty different occasions in different nations and was successfully contained every time, can still create havoc to such an extent that eventually it had to be declared an international public health emergency $(2,3)$. It has been realized that the existence of an effective public healthcare delivery system is a must to successfully counter the disease outbreaks, and is extremely difficult to develop such systems after the crisis has occurred, and absence of the same can allow even a less infectious disease (viz. moderately long incubation period, individuals being non-infectious during the incubation period, absence of airborne transmission - all factors which do not favor rapid transmission) to grow at an exponential rate $(4,5)$.

The 2014 outbreak of Ebola Virus Disease (EVD) has exposed multiple weaknesses in the public healthcare delivery system (viz. delayed initial response, nil or minimal number of isolation wards, extremely poor doctor-population ratio, human resource shortage, logistics constraints - personal protective equipments, inability to involve members of the community, limited awareness campaigns for people, etc.) and shortcomings in the research arena (viz. non-availability of prophylactic or therapeutic options) (1,4,6-8). In addition, the outbreak has unmasked the ever-growing socio-economic disparities in the different sections of the world, where the higher sections of the society get the best care and poor people have to fight for their survival without any ray of hope $(4,9)$. The recent updates suggest that after claiming lives of thousands of people (including doctors, nursing staff, healthcare workers, etc.), two nations - Senegal and Nigeria have been declared as Ebola-free $(5,10,11)$. However, it does not mean that the unaffected nations can relax under the misconception that the threat no more exists $(1,12)$. The ground reality is that anytime and anywhere in the globe new chain of transmission can start, even if there is a single lapse in the detection of an infectious case, or isolation of a symptomatic contact, or a failure in infection control/burial of the deceased $(1,5,6)$.

Realizing the aftermaths associated with the Ebola disease, the World Health Organization (WHO) has advocated the development of a systematic framework to successfully combat the appearance of even a single case, in nations, where no suspect/confirmed case of Ebola has been detected till date (13). This proposed framework should essentially be composed of strategies for the preparedness - creation of a Regional Ebola Emergency Preparedness and Response Plan (viz. provisions for mobilization of sufficient human resources to implement Ebola response measures; measures to ensure community participation; ascertaining laboratories for work related with diagnosis of Ebola; logistics support; infection prevention and control measures; travel and trade related recommendations; awareness campaigns for the community regarding different preventive measures; establishment of a data collection system; mechanism for surveillance and followup; establishment of Ebola treatment centers; and guidelines to ensure coordination and crisis management at different levels) $(14,15)$. In addition, steps for an appropriate response (viz. alert management - by creation of an alert system in well-defined sites, creation of a rapid response team trained in case definitions, reporting, and infection prevention and control measures), and periodic monitoring and evaluation is also recommended (13-15). In case, any patient is diagnosed with EVD, details about the same are notified to the WHO within a period of six hours, and then response strategies are implemented, including daily medical follow-up of the patient's contacts for 21 days after exposure $(1,3,6)$.

To conclude, in order to avoid any future major outbreak in the non-affected nations, the onus lie on the public health authorities and their ability to develop and implement a comprehensive preparedness plan in conformity with the recommendations proposed by the international agencies.

\section{Ethical issues}

Not applicable.

Competing interests

Authors declare that they have no competing interests.

Authors' contributions

SRS conceived about the study design and wrote the manuscript. PSS searched for the review of literature. JR supervised the overall process and epidemiologic interpretation of the information. All authors approved the final version of the manuscript. 


\section{References}

1. Frieden TR, Damon I, Bell BP, Kenyon T, Nichol S. Ebola 2014-new challenges, new global response and responsibility. $N$ Engl J Med 2014; 371: 1177-80. doi: 10.1056/nejmp1409903

2. Centers for Disease Control and Prevention. Outbreaks chronology: Ebola virus disease [internet]. Atlanta: CDC; 2014. [Cited 2014 Oct 22]. Available from: http://www.cdc.gov/vhf/ Ebola/outbreaks/history/chronology.html

3. Briand S, Bertherat E, Cox P, Formenty P, Kieny MP, Myhre JK, et al. The international Ebola emergency. N Engl J Med 2014; 371: 1180-3. doi: 10.1056/nejmp1409858

4. Chan M. Ebola virus disease in West Africa - no early end to the outbreak. N Engl J Med 2014; 371: 1183-5. doi: 10.1056/ nejmp1409859

5. World Health Organization (WHO). Ebola in West Africa: heading for catastrophe? [internet]. 2014. [Cited 2014 Oct 10]. Available from: http://www.who.int/csr/disease/Ebola/Ebola-6-months/ west-africa/en/

6. World Health Organization (WHO). Ebola virus disease - Fact sheet $\mathrm{N}^{\circ} 103 ;$ 2014. [Cited 2014 Oct 15]. Available from: http:// www.who.int/mediacentre/factsheets/fs103/en/

7. Marzi A, Feldmann $H$. Ebola virus vaccines: an overview of current approaches. Expert Rev Vaccines 2014; 13: 521-31. doi: 10.1586/14760584.2014.885841

8. Oestereich L, Ludtke A, Wurr S, Rieger T, Munoz-Fontela C,
Gunther S. Successful treatment of advanced Ebola virus infection with T-705 (favipiravir) in a small animal model. Antiviral Res 2014; 105: 17-21. doi: 10.1016/j.antiviral.2014.02.014

9. Fauci AS. Ebola - underscoring the global disparities in health care resources. N Engl J Med 2014; 371: 1084-6. doi: 10.1056/ nejmp1409494

10. World Health Organization (WHO). WHO congratulates Senegal on ending Ebola transmission [internet]. 2014. [Cited 2014 Oct 18]. Available from: http://www.who.int/mediacentre/news/ statements/2014/senegal-ends-ebola/en/

11. World Health Organization (WHO). WHO declares end of Ebola outbreak in Nigeria [internet]. 2014. [Cited 2014 Oct 26]. Available from: http://who.int/mediacentre/news/statements/2014/nigeriaends-ebola/en/

12. Kanapathipillai R. Ebola virus disease--current knowledge. $N$ Engl J Med 2014; 371: e18. doi: 10.1056/nejmp1410741

13. Green A. WHO and partners launch Ebola response plan. Lancet 2014; 384: 481. doi: 10.1016/s0140-6736(14)61322-2

14. World Health Organization (WHO). Public health events of initially unknown etiology: A framework for preparedness and response in the African Region. Geneva: WHO; 2014.

15. Hwang ES. Preparedness for prevention of Ebola virus disease. J Korean Med Sci 2014; 29: 1185. doi: 10.3346/ jkms.2014.29.9.1185 